\title{
Regioselective Glucosylation of Pyridoxine by Microorganisms
}

\author{
Yasuhisa AsAno and Koichi W ADA $^{\dagger}$ \\ Biotechnology Research Center, Toyama Prefectural University, 5180 Kurokawa, Kosugi, \\ Toyama 939-0398, Japan
}

Received August 1, 2002; Accepted November 13, 2002

\begin{abstract}
Microorganisms from culture collections and isolates from nature were screened for the ability to catalyze the regioselective glucosylation of pyridoxine (PN) to produce pyridoxine $5^{\prime}$ - $\alpha$-D-glucoside $\left(\mathbf{P N}-5^{\prime}-\alpha\right.$-G) or pyridoxine $4^{\prime}-\alpha$-D-glucoside $\left(\mathrm{PN}-4^{\prime}-\alpha-\mathrm{G}\right)$. Transglucosylation activity specific to $5^{\prime}$-position of $P N$ was found in fungi belonging to genera such as Coriolus and Verticillium, and activity at the $4^{\prime}$-position of PN was found in bacteria belonging to genera such as Bacillus and Serratia. From $100 \mathrm{~mm}$ PN, intact cells of Verticillium dahliae TPU 4900 produced $42 \mathrm{mM}$ $(13.9 \mathrm{mg} / \mathrm{mL}) \mathbf{P N}-5^{\prime}-\alpha-G$ after $70 \mathrm{~h}$ of reaction. Intact cells of Bacillus cereus TPU 5504 produced $33 \mathrm{~mm}$ $(10.9 \mathrm{mg} / \mathrm{mL}) \mathrm{PN}^{\prime} 4^{\prime}-\alpha-\mathrm{G}$ after $19 \mathrm{~h}$ of reaction. The selectivities for $5^{\prime}$ - and $4^{\prime}$-positions were $80 \%$ and $90 \%$, respectively.
\end{abstract}

Key words: Verticillium; Coriolus; Bacillus; pyridoxine $5^{\prime}-\alpha$-D-glucoside; pyridoxine $4^{\prime}-\alpha$-D-glucoside

Pyridoxine $\alpha$-D-glucoside (PN- $\alpha-\mathrm{G}$ ) is nutritionally important as vitamin $\mathrm{B}_{6},{ }^{1)}$ and is more stable than PN against light and heat. ${ }^{2}$ Two compounds, pyridoxine $5^{\prime}-\alpha$-D-glucoside $\left(\mathrm{PN}-5^{\prime}-\alpha-\mathrm{G}\right)$ and pyridoxine $4^{\prime}-\alpha-\mathrm{D}-$ glucoside $\left(\mathrm{PN}-4^{\prime}-\alpha-\mathrm{G}\right)$ are positional isomers of $\mathrm{PN}$ $\alpha-\mathrm{G}^{3)}$ (Fig. 1), and the former is hydrolyzed by liver cells to PN more easily than the latter. ${ }^{4)}$ Anomer selective and regioselective introduction of the glucosyl group into $\mathrm{PN}$ is needed for the production of $\mathrm{PN}-5^{\prime}-\alpha-\mathrm{G}$. In the chemical glucosylation of $\mathrm{PN}$ in the $5^{\prime}$ - or $4^{\prime}$-position, it is necessary to protect the functional groups of PN and glucose, and to quench the $\beta$-anomer with $\beta$-glucosidase. ${ }^{3)}$

The enzymatic glucosylation of $\mathrm{PN}$ with several microorganisms and enzymes has been studied, but selectivity for the $5^{\prime}$-position and yield of PN- $\alpha$-G are low. Micrococcus luteus (formerly Sarcina lutea) produces $\mathrm{PN}-\alpha-\mathrm{G}$ that consists of a large amount of PN-5' $-\alpha-\mathrm{G}$ and a small amount of PN- $4^{\prime}-\alpha-\mathrm{G}$ (molar ratio, about $4: 1$ ) from sucrose and PN., ${ }^{3,5}$ Furthermore, $\alpha$-glucosidase from Mucor javanicus forms $\mathrm{PN}-5^{\prime}-\alpha-\mathrm{G}$ and $\mathrm{PN}-4^{\prime}-\alpha-\mathrm{G}$ at the molar ratio of $1: 1$ from dextrin and PN. ${ }^{6}$ In addition, cyclomaltodextrin glucanotransferase (CGTase) from Bacillus stearothermophilus and Paenibacillus macerans (formerly Bacillus macerans) formed $\mathrm{PN}-5^{\prime}-\alpha-\mathrm{G}$ and PN-4' $-\alpha-\mathrm{G}$ at the molar ratio $1: 1.4$ to $1: 1.8$ from dextrin and PN. ${ }^{6,7)} 4^{\prime}$-Position-selective $\alpha$-glucosidases from baker's yeast, B. stearothermophilus, and

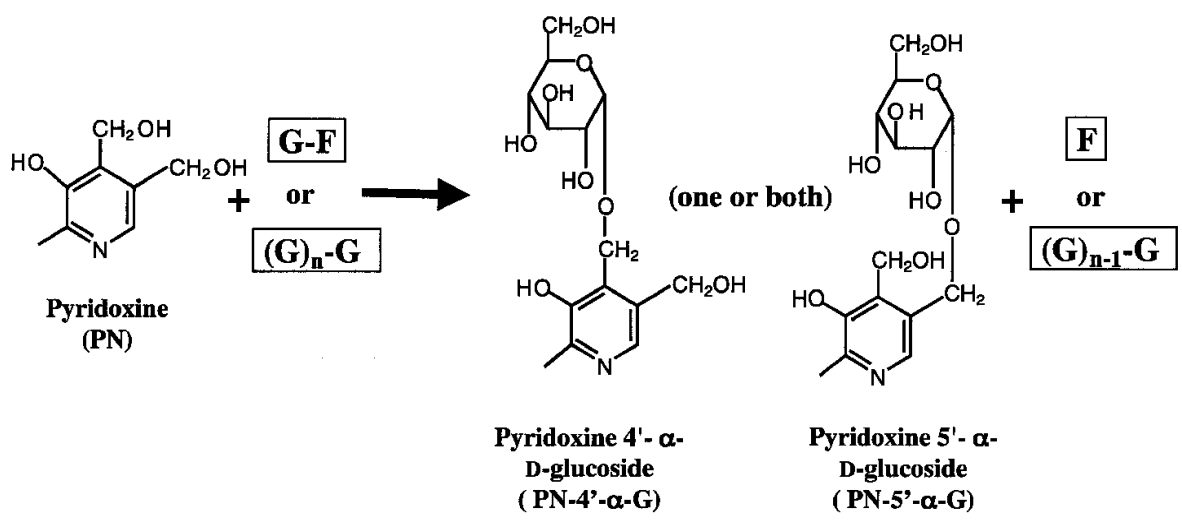

Fig. 1. Enzymatic Synthesis of Pyridoxine $\alpha$-D-Glucoside.

Abbreviations: G-F, sucrose; $(\mathrm{G})_{\mathrm{n}}-\mathrm{G}$, dextrin; F, fructose.

${ }^{\dagger}$ To whom correspondence should be addressed. Research Institute, Daiichi Fine Chemical Co., Ltd., 530 Chokeiji, Takaoka, Toyama 933-8511, Japan. Tel: +81-766-26-4409; Fax: +81-766-26-4462; E-mail: k-wada@daiichi-fcj.co.jp

Abbreviations: CGTase, cyclomaltodextrin glucanotransferase; PN, pyridoxine; PN-5' $-\alpha-\mathrm{G}$, pyridoxine $5^{\prime}-\alpha-\mathrm{D}-\mathrm{glucoside}$; PN-4'- $\alpha-\mathrm{G}$, pyridoxine $4^{\prime}-\alpha$-D-glucoside; $\mathrm{PN} \cdot \mathrm{HCl}$, pyridoxine hydrochloride 
rice produce only $\mathrm{PN}-4^{\prime}-\alpha-\mathrm{G}$ from maltose and $\mathrm{PN}{ }^{8)}$ There has been no report about a microorganism or enzyme that transfers a glucosyl group to the $5^{\prime}$-position of $\mathrm{PN}$ in high yield.

To produce $\mathrm{PN}-5^{\prime}-\alpha-\mathrm{G}$ as a useful and stable vitamin $B_{6}$ derivative with easy isolation and purification, it is necessary to obtain microorganisms that have the activity of transglucosylation specific to $5^{\prime}$-position of PN. In this paper, we describe the results of screening for microorganisms catalyzing regioselective formation of $\mathrm{PN}-\alpha-\mathrm{G}$ from sucrose, dextrin, or both.

\section{Materials and Methods}

Chemicals. Pyridoxine hydrochloride $(\mathrm{PN} \cdot \mathrm{HCl})$ was provided to us by Daiichi Fine Chemical Co., Ltd. (Toyama, Japan). Dextrin (TK-16) was purchased from Matsutani Chemical Industries Co., Ltd. (Hyogo, Japan). CGTase (from Paenibacillus macerans) was purchased from Amano Enzyme Inc. (Aichi, Japan). Glucoamylase (from Rhizopus niveus) was purchased from Seikagaku Co. (Tokyo, Japan). All other chemicals used were commercially available and were of analytical grade.

Medium. Medium I for screening contained 2.0\% dextrin, $2.0 \%$ sucrose, $1.0 \%$ peptone, $0.05 \%$ yeast extract, $\quad 0.5 \% \quad \mathrm{~K}_{2} \mathrm{HPO}_{4}, \quad 0.1 \% \quad \mathrm{KH}_{2} \mathrm{PO}_{4}, \quad 0.02 \%$ $\mathrm{FeSO}_{4} \cdot 7 \mathrm{H}_{2} \mathrm{O}, 0.02 \% \mathrm{MgSO}_{4} \cdot 7 \mathrm{H}_{2} \mathrm{O}, 0.01 \% \mathrm{MnSO}_{4}$. $5 \mathrm{H}_{2} \mathrm{O}$, and $0.1 \% \mathrm{PN} \cdot \mathrm{HCl}$ in tap water at $\mathrm{pH} 7.0$. The medium for plate was solidified by the addition of $2.0 \%$ agar. Medium II for flask culture of microorganisms forming $\mathrm{PN}-5^{\prime}-\alpha-\mathrm{G}$ contained $4 \%$ soluble starch, 1\% Esusan meat (Ajinomoto Co., Inc., Tokyo), $0.1 \% \mathrm{KH}_{2} \mathrm{PO}_{4}, 0.05 \% \mathrm{KCl}, 0.05 \% \mathrm{MgSO}_{4}$. $7 \mathrm{H}_{2} \mathrm{O}, 0.001 \% \mathrm{FeSO}_{4} \cdot 7 \mathrm{H}_{2} \mathrm{O}$, and $0.1 \% \mathrm{PN} \cdot \mathrm{HCl}$ in tap water at $\mathrm{pH}$ 7.0.

Microorganisms. Microorganisms from culture collections (907 strains), isolates from waste water of industrial plants (Daiichi Fine Chemical Co., Ltd.) of $\mathrm{PN} \cdot \mathrm{HCl}$ (53 strains), and isolates from contaminated $\mathrm{PN}-\alpha-\mathrm{G}$ solutions (10 strains) were screened. Type cultures were from the Institute of Molecular and Cellular Biosciences (IAM), University of Tokyo; the Institute of Fermentation (IFO), Osaka, Japan; the Japan Collection of Microorganisms (JCM), Tokyo; and our laboratory (TPU, Toyama Prefectural University).

We suspended $1 \mathrm{~mL}$ of waste water in $15 \mathrm{~mL}$ of medium I (final concentration of $\mathrm{PN} \cdot \mathrm{HCl}, 5 \%$ ) in a $100-\mathrm{mL}$ flask, and the flask was shaken for $7-10 \mathrm{~d}$ at $30^{\circ} \mathrm{C}$. One milliliter of the culture was used to inoculate freshly prepared medium, which was incubated. This procedure was repeated once more, and a small volume of the culture medium was spread on plates of medium I. Separately, a mass of microorganisms that had grown spontaneously on five solutions of $\mathrm{PN}-\alpha-\mathrm{G}$ was suspended in a small volume of sterilized $0.1 \%$ Tween 80 and spread on plates of medium I. The plates were incubated at $30^{\circ} \mathrm{C}$ and colonies were isolated.

Screening. Microorganisms from culture collections and isolates from nature were grown on $5 \mathrm{~mL}$ of medium I in test tubes $(\phi 16.5 \times 165 \mathrm{~mm})$ for 2-14 d (until the microorganisms were growing well) at $30^{\circ} \mathrm{C}$ with shaking, and some fungal strains were cultured at $25^{\circ} \mathrm{C}$. The culture broth was boiled for $10 \mathrm{~min}$, and centrifuged $(16,000 \times \mathrm{g}$, for $10 \mathrm{~min})$ to remove the cells, the supernatant was examined by HPLC.

Preparation of authentic samples of $P N-5^{\prime}-\alpha-G$ and $P N-4^{\prime}-\alpha-G$. The method of Suzuki et al. ${ }^{6}$ was modified for preparation of authentic samples of PN$5^{\prime}-\alpha-\mathrm{G}$ and PN-4'- $\alpha-\mathrm{G}$ with the use of CGTase. The reaction mixture consisted of $12 \mathrm{~mL}$ of $100 \mathrm{mM}$ potassium phosphate buffer $(\mathrm{pH} 7.0)$ containing $0.37 \mathrm{~g}(1.8 \mathrm{mmol})$ of $\mathrm{PN} \cdot \mathrm{HCl}, 0.96 \mathrm{~g}$ of dextrin, $0.10 \mathrm{mg} \mathrm{CaCl} \cdot 2 \mathrm{H}_{2} \mathrm{O}$, and 1440 units of CGTase (one unit of CGTase activity was defined by the method of Tilden and Hudson ${ }^{9)}$ ). The reaction was done at $30^{\circ} \mathrm{C}$ for $144 \mathrm{~h}$ in the dark and was stopped by boiling of the mixture for $10 \mathrm{~min}$. Glucoamylase treatment $\left(30^{\circ} \mathrm{C}, 17 \mathrm{~h}\right)$ was done to convert pyridoxine $\alpha$-maltosides, that appeared as byproducts, to $\mathrm{PN}-5^{\prime}-\alpha-\mathrm{G}$ or $\mathrm{PN}-4^{\prime}-\alpha-\mathrm{G}$. After the reaction mixture was evaporated under reduced pressure and put on a Sephadex LH-20 column $(\phi 14.5 \times$ 1200 mm, Amersham Bioscience Corp., Piscataway, NJ), a mixture of $\mathrm{PN}-5^{\prime}-\alpha-\mathrm{G}$ and $\mathrm{PN}-4^{\prime}-\alpha-\mathrm{G}$ was eluted with $20 \%(\mathrm{v} / \mathrm{v})$ methanol. The mixture was injected into an ODS column for preparative HPLC (YMC-pack ODS column SH-343-5, $\phi 20 \times 250 \mathrm{~mm}$, YMC Co., Ltd., Kyoto) and then eluted with $4 \%$ $(\mathrm{v} / \mathrm{v})$ methanol at the flow rate of $3.5 \mathrm{~mL} / \mathrm{min}$. The fractions containing only $\mathrm{PN}-5^{\prime}-\alpha-\mathrm{G}$ were combined and evaporated to dryness, and $94 \mathrm{mg}$ of powder was obtained. From the fractions containing only PN-4' $\alpha-\mathrm{G}, 74 \mathrm{mg}$ of powder was obtained.

Analysis of $P N-\alpha-G$. PN, PN- $5^{\prime}-\alpha-\mathrm{G}$, and $\mathrm{PN}-4^{\prime}-$ $\alpha-\mathrm{G}$ were analyzed by HPLC with a Cosmosil $5 \mathrm{C}_{18} \mathrm{AR}$ column $(\phi 4.6 \times 150 \mathrm{~mm}$, Nakalai Tesque, Inc., Kyoto) with detection at $325 \mathrm{~nm}$. The mobile phase was $1 \%(\mathrm{v} / \mathrm{v})$ methanol, and the flow rate was $0.8 \mathrm{~mL} / \mathrm{min}$ at $30^{\circ} \mathrm{C}$. Selectivity (\%) for the $5^{\prime}$-position of PN was calculated as the amount of $\mathrm{PN}-5^{\prime}-\alpha-$ $G$ divided by the amounts of sum of $\mathrm{PN}-5^{\prime}-\alpha-\mathrm{G}$ and PN-4' $-\alpha-\mathrm{G}$, with the result multiplied by 100 . The selectivity at the $4^{\prime}$-position was calculated in a similar way.

Synthesis of $P N-5^{\prime}-\alpha-G$ by intact cells. Coriolus 
Table 1. Number of Strains with High Regioselectivity

\begin{tabular}{|c|c|c|c|c|c|c|c|c|c|c|}
\hline & & & \multicolumn{2}{|c|}{$\begin{array}{l}\text { Number of } \\
\text { microorganisms tested }\end{array}$} & \multicolumn{3}{|c|}{$\begin{array}{l}\text { Number of strains with } \\
5^{\prime} \text {-position selectivity* }\end{array}$} & \multicolumn{3}{|c|}{$\begin{array}{l}\text { Number of strains with } \\
4^{\prime} \text {-position selectivity* }\end{array}$} \\
\hline & & & Genera & Strains & \multicolumn{3}{|c|}{ Yield of PN-5' $-\alpha$-G in culture, mM } & \multicolumn{3}{|c|}{ Yield of PN-4' $-\alpha-\mathrm{G}$ in culture, $\mathrm{mM}$} \\
\hline \multirow{5}{*}{\multicolumn{2}{|c|}{ Culture collection }} & Bacteria & 37 & 307 & $4(0)$ & $1(0)$ & $0 \quad(0)$ & $20 \quad(9)$ & $10 \quad(5)$ & \\
\hline & & Actinomycetes & 8 & 87 & $1 \quad(0)$ & $0 \quad(0)$ & $0 \quad(0)$ & $2(0)$ & $1 \quad(0)$ & $0 \quad(0)$ \\
\hline & & Yeasts & 23 & 235 & 4 (1) & $0 \quad(0)$ & $0 \quad(0)$ & $6(1)$ & $1 \quad(1)$ & 0 \\
\hline & & Fungi & 61 & 278 & $36(12)$ & $14(12)$ & $6(5)$ & $12(0)$ & $5(0)$ & $1(0)$ \\
\hline & & Total & 129 & 907 & $45(13)$ & $15(12)$ & $6(5)$ & $40(10)$ & $17 \quad(6)$ & $1(0)$ \\
\hline \multirow{5}{*}{$\begin{array}{l}\text { Isolated } \\
\text { strain }\end{array}$} & from waste & Not fungi & & 40 & $0 \quad(0)$ & $0 \quad(0)$ & $0 \quad(0)$ & $1 \quad(0)$ & $1 \quad(1)$ & $0 \quad(0)$ \\
\hline & water & Fungi & & 13 & $0 \quad(0)$ & $0 \quad(0)$ & $0 \quad(0)$ & $0 \quad(0)$ & $0 \quad(0)$ & $0 \quad(0)$ \\
\hline & from contaminated & Not fungi & & 6 & $0 \quad(0)$ & $0 \quad(0)$ & $0 \quad(0)$ & $2(0)$ & $0 \quad(0)$ & $0 \quad(0)$ \\
\hline & PN- $\alpha$-G-solution & Fungi & & 4 & $0 \quad(0)$ & $1 \quad(0)$ & $0 \quad(0)$ & $0 \quad(0)$ & $0 \quad(0)$ & $0 \quad(0)$ \\
\hline & & Total & & 63 & $0 \quad(0)$ & $1 \quad(0)$ & 0 & $3(0)$ & 1 (1) & $0 \quad(0)$ \\
\hline
\end{tabular}

* Regioselectivity was calculated at the amount of PN-5' $-\alpha-\mathrm{G}$ or PN-4' $-\alpha-\mathrm{G}$ divided by the amounts of sum of PN-5'- $\alpha-\mathrm{G}$ and PN-4 $-\alpha-\mathrm{G}$, with the result multiplied by 100 . Strain with regioselectivity of more than $75 \%$ was defined as a strain with $5^{\prime}$ - or $4^{\prime}$-position selectivity.

The numbers of strains with regioselectivity of more than $90 \%$ are given parentheses.

fibula IFO 4949 and Coriolus pubescens IFO 9782 were cultured on $100 \mathrm{~mL}$ of medium II in $500-\mathrm{mL}$ flasks on a rotary shaker $(200 \mathrm{rpm})$ at $25^{\circ} \mathrm{C}$ for $7 \mathrm{~d}$. Verticillium dahliae TPU 4900 was cultured on the same medium at $20^{\circ} \mathrm{C}$ for $11 \mathrm{~d}$. The cells were harvested by filtration with suction and then washed with distilled water. The reaction mixture for $\mathrm{PN}-5^{\prime}$ $\alpha-\mathrm{G}$ synthesis consisted of $1.2 \mathrm{~mL}$ of $100 \mathrm{~mm}$ potassium phosphate buffer containing $24.7 \mathrm{mg}(0.12 \mathrm{mmol})$ of $\mathrm{PN} \cdot \mathrm{HCl}, 24 \mathrm{mg}$ of dextrin, and the cells harvested from $1.0 \mathrm{~mL}$ of culture broth $(52 \mathrm{mg}$ of $C$. fibula IFO 4949, $50 \mathrm{mg}$ of $C$. pubescens IFO 9782, or $109 \mathrm{mg}$ of $V$. dahliae TPU 4900, wet weights). The reactions were done at pH 5.0-6.5 (adjusted with $\mathrm{NaOH}$ ) and $40^{\circ} \mathrm{C}$ for $96 \mathrm{~h}$ with shaking in the dark, and then 84 mg of dextrin was added each of three times, at 20, 40 , and $70 \mathrm{~h}$, and an equal amount of cells was added at $40 \mathrm{~h}$.

Synthesis of $P N-4^{\prime}-\alpha-G$ by intact cells. Bacillus cereus TPU 5504 was cultured on $150 \mathrm{~mL}$ of medium $\mathrm{I}$ in a $500-\mathrm{mL}$ flask on the rotary shaker at $30^{\circ} \mathrm{C}$ for $4 \mathrm{~d}$. The cells were harvested by centrifugation $(8200$ $\times g$ for $15 \mathrm{~min}$ ) and then washed with distilled water. The reaction mixture for $\mathrm{PN}-4^{\prime}-\alpha-\mathrm{G}$ synthesis consisted of $250 \mathrm{~mL}$ of $100 \mathrm{~mm}$ potassium phosphate buffer containing $5.1 \mathrm{~g}(25 \mathrm{mmol})$ of $\mathrm{PN} \cdot \mathrm{HCl}, 5.0 \mathrm{~g}$ of dextrin, and the cells harvested from $500 \mathrm{~mL}$ of culture broth $(9.7 \mathrm{~g}$, wet weight) in a $500 \mathrm{~mL}$-flask. The reactions were done at $\mathrm{pH}$ 6.0-7.5 (adjusted with $\mathrm{NaOH}$ ) and $40^{\circ} \mathrm{C}$ for $48 \mathrm{~h}$ with stirring in the dark. An equal amount of dextrin was added at $6 \mathrm{~h}$ and $26 \mathrm{~h}$, and an equal amount of cells was added at $26 \mathrm{~h}$.

\section{Results}

Screening for microorganisms forming $P N-\alpha-G$ from stock cultures

Nine hundred and seven strains from stock cul- tures of TPU, IAM, IFO, and JCM were grown in medium $I$ and then analyzed. Strains that yielded PN-5' $-\alpha-\mathrm{G}$ in more than $1.5 \%$ molar yield (about $0.08 \mathrm{mM}$ ) and had $5^{\prime}$-position selectivity in more than $75 \%$ were selected as $5^{\prime}$-position-selective strains, and $4^{\prime}$-position-selective strains were selected in a similar way. The numbers of selective strains of both kinds are listed in Table 1.

Of the bacteria examined (307 strains in 37 genera), there were more $4^{\prime}$-position-selective strains than that of $5^{\prime}$-position selective ones. $4^{\prime}$-Position selectivity was found in nine genera: Arthrobacter, Bacillus, Corynebacterium, Edwardsiella, Hafnia, Ochrobactrum, Salmonella, Serratia, and Xanthobacter (31 strains, $10 \%$ of tested bacteria). 5'Position-selectivity was found in the genera Corynebacterium and Paenibacillus (4 strains). Nonselective activity to form $\mathrm{PN}-\alpha-\mathrm{G}$ was seen in five genera of bacteria: Cedecea, Enterobacter, Kocuria, Micrococcus, and Pseudomonas. Neither PN-5' $-\alpha-\mathrm{G}$ nor PN$4^{\prime}-\alpha-\mathrm{G}$ was produced in more than $1.5 \%$ molar yield by the strain of Achromobacter, Acinetobacter, Aeromonas, Agrobacterium, Alcaligenes, Citrobacter, Comamonas, Curtobacterium, Erwinia, Escherichia, Flavobacterium, Klebsiella, Kluyvera, Methylobacterium, Morganella, Pantoea, Pimelobacter, Proteus, Providencia, Thiobacillus, Variovorax, or Yersinia. Of bacteria that accumulated PN$5^{\prime}-\alpha-\mathrm{G}$ or $\mathrm{PN}-4^{\prime}-\alpha-\mathrm{G}$ in more than $15 \%$ molar yield $(0.75 \mathrm{mM})$ in the culture broth, there were ten $4^{\prime}$ position-selective strains (5 strains with selectivity of more than 90\%), but Paenibacillus alvei IFO 3343 was the only $5^{\prime}$-position-selective strain.

Of the actinomycetes ( 87 strains in 8 genera), Pseudonocardia autotrophica TPU 3870 was the only 5 '-position-selective strain, but three strains of the genus Nocardia or Rhodococcus were 4'-positionselective. The actinomycetes from Gordona, Mycobacterium, and Streptomyces had nonselective 
PN- $\alpha$-G-forming activity. Strains from Actinomyces, Nocardioides, and Rothia formed neither PN-5'- $\alpha-\mathrm{G}$ nor $\mathrm{PN}-4^{\prime}-\alpha-\mathrm{G}$ in more than $1.5 \%$ molar yield.

Of yeasts (235 strains in 23 genera), three strains of Cryptococcus were 5'-position-selective, and six strains from Nakazawaea, Saccharomyces, and Zygosaccharomyces were 4'-position-selective. Only one strain, Saccharomyces heterogenicus TPU 1043, both produced $\mathrm{PN}-4^{\prime}-\alpha-\mathrm{G}$ with a high molar yield $(27 \%)$ in the culture broth and had high $4^{\prime}$-position selectivity $(97 \%)$. Yeasts with nonselective $\mathrm{PN}-\alpha-\mathrm{G}-$ forming activity were found in seven genera: Candida, Debaryomyces, Hansenula, Pichia, Rhodotorula, Schizosaccharomyces, and Sporobolomyces. Strains belonging to 12 genera, Brettanomyces, Geotrichum, Hanseniaspora, Kloeckera, Kluyueromyces, Lipomyces, Rhodosporidium, Saccharomycodes, Saccharomycopsis, Torulopsis, Trichosporon, and Williposis, yielded neither PN-5'$\alpha-\mathrm{G}$ nor $\mathrm{PN}-4^{\prime}-\alpha-\mathrm{G}$ in more than $1.5 \%$ molar yield.

Of the 278 strains in 61 genera of fungi tested, 56 strains from Coriolus, Eurotium, Flammulina, Ganoderma, Gliocladium, Helicostylum, Mortierella, Pithomyces, Schizophyllum, Trametes, and Verticillium had 5'-position selectivity. Seventeen of them $\left(30 \%\right.$ of the $5^{\prime}$-position selective fungi) produced $\mathrm{PN}-5^{\prime}-\alpha-\mathrm{G}$ in more than $15 \%$ molar yield $(0.75 \mathrm{mM})$ and with $5^{\prime}$-position selectivity of more than $90 \%$. Seventeen other strains $(6 \%$ of the fungi tested) produced $\mathrm{PN}-4^{\prime}-\alpha-\mathrm{G}$ in high $4^{\prime}$-position selectivity, but all at less than $90 \%$. These strains were in six genera: Beauveria, Fusarium, Mortierella, Penicillium, Tritirachium, and Verticillium. Fungi forming $\mathrm{PN}-\alpha-\mathrm{G}$ nonregioselectively were found among Acremonium, Armillariella, Aspergillus, Caldariomyces, Chaetosartorya, Cladosporium, Dactylaria, Edyuillia, Gibberella, Neurospora, Panus, and Phytophthora. Strains from Absidia, Arthroderma, Aureobasidium, Chaetomium, Chrysosporium, Coprinus, Cryptoporus, Cunninghamella, Cylindrocarpon, Daedalea, Daedaleopsis, Exophiala, Gloeophyllum, Grifola, Hypocrea, Irpex, Keratinomyces, Laetiporus, Lentinus, Lepista, Mucor, Neosartorya, Neurospora, Pholiota, Phycomyces, Phytophthora, Pleurotus, Polyporus, Pycnoporus, Rhizopus, Sporothrix, Talaromyces, Trichophyton, and Zygorhynchus produced neither PN-5' $-\alpha-\mathrm{G}$ nor PN- $4^{\prime}-\alpha-\mathrm{G}$ in more than $1.5 \%$ molar yield.

Screening isolated strains for microorganisms forming $P N-\alpha-G$

We isolated 53 microorganisms (including 13 fungal strains) from waste water of an industrial plant for $\mathrm{PN} \cdot \mathrm{HCl}$ and 10 microorganisms (including 4 fungal strains) from contaminated $\mathrm{PN}-\alpha-\mathrm{G}$ solutions. The proportions of $\mathrm{PN}-5^{\prime}-\alpha-\mathrm{G}$ and $\mathrm{PN}-4^{\prime}-\alpha-\mathrm{G}$ in cultures of these isolated microorganisms varied widely.
One unidentified fungal strain with arthroconidium, named I-1, isolated from the contaminated solution produced $\mathrm{PN}-5^{\prime}-\alpha-\mathrm{G}$ with a high molar yield (21\%) and high $5^{\prime}$-position selectivity (89\%). One bacterial strain, named F-2-1, isolated from waste water, was selected as a microorganism that produced PN-4' $-\alpha$ $\mathrm{G}$ with a high molar yield (24\%) and high $4^{\prime}$-position selectivity $(92 \%)$. The characteristics of strain F-2-1 were as follows; Gram-positive rods (0.8-1.0 $\times$ 2.0-3.0 $\mu \mathrm{m})$, aerobic, spore-forming, non-motile, catalase-positive, oxidase-negative, and O-F-test negative. Strain F-2-1 belonged to Bacillus, according to information in Bergey's Manual of Systematic Bacteriology. ${ }^{10)}$

\section{Formation of $P N-5^{\prime}-\alpha-G$ by selected strains}

During this survey, strains that yielded PN-5' $-\alpha-\mathrm{G}$ with molar conversion of more than $15 \%(0.75 \mathrm{mM})$ and that had $5^{\prime}$-position selectivity of more than $75 \%$ were selected (Table 2). Of the bacteria, only Paenibacillus alvei IFO 3343 had both qualities. Fungi from stock cultures with qualities were limited to 20 strains of only eight species in four genera: Coriolus, Flammulina, Schizophyllum, and Verticillium. Four strains in the genera Coriolus and Verticillium had of $95 \%$ and more $5^{\prime}$-position selectivity.

Results of investigation of transglucosylation activity from sucrose and dextrin to $100 \mathrm{mM} \mathrm{PN}$ in the culture of eight selected strains in media I and II are shown in Table 3. Medium II gave 1.2- to 10-fold activity per volume of culture medium than medium I. Both activity and 5'-selectivity with Coriolus fibula IFO 4949, Coriolus pubescens IFO 9782, and Verticillium dahliae TPU 4900 were higher than with other strains, even in the presence of this high concentration of PN (100 mM).

\section{Synthesis of $P N-5^{\prime}-\alpha-G$ by intact cells}

Next we examined reactions with these three selected strains harvested from flask cultures with medium II. We used $100 \mathrm{~mm} \mathrm{PN}$ as the aglycon and dextrin added intermittently as the glucosyl group donor, because preliminary experiments showed cells of these strains could not use sucrose as a glucosyl group donor (results not shown). In the three reaction mixtures, seven unidentified peaks (Fig. 2, peaks A-G) during HPLC of a sample taken after the yield of $\mathrm{PN}-5^{\prime}-\alpha-\mathrm{G}$ reached a maximum. Treatment of the reaction mixture with glucoamylase caused a decrease in the area of peak $F$ and an increase in the area of $\mathrm{PN}-5^{\prime}-\alpha-\mathrm{G}$, and all of these peaks were converted to PN by hydrolysis with $\alpha$-glucosidase (not shown). Terefore, although the peaks have not been identified yet, we presumed that peak $\mathrm{F}$ was pyridoxine $5^{\prime}-\alpha$-maltoside, and that the other peaks were other PN glycosides, such as pyridoxine 3- $\alpha$-Dglucoside and pyridoxine $4^{\prime}, 5^{\prime}$ - $\alpha$-diglucoside. ${ }^{7}$

With C. fibula IFO 4949 and C. pubescens IFO 
Table 2. Microorganism with High 5'-Position-selective Glucosylation

\begin{tabular}{|c|c|c|c|c|c|}
\hline & \multirow{2}{*}{$\begin{array}{l}\text { Culture time } \\
\text { (d) }\end{array}$} & \multirow{2}{*}{$\begin{array}{l}\text { Culture temp. } \\
\qquad\left({ }^{\circ} \mathrm{C}\right)\end{array}$} & \multicolumn{2}{|c|}{ Compound found in culture (mм) } & \multirow{2}{*}{$\begin{array}{c}\text { 5'-Position selectivity } \\
(\%)\end{array}$} \\
\hline & & & $\mathrm{PN}-4^{\prime}-\alpha-\mathrm{G}$ & $\mathrm{PN}-5^{\prime}-\alpha-\mathrm{G}$ & \\
\hline \multicolumn{6}{|l|}{ Bacterium } \\
\hline Paenibacillus alvei IFO 3343 & 6 & 30 & 0.27 & 1.56 & 85.4 \\
\hline \multicolumn{6}{|l|}{ Fungi } \\
\hline Coriolus consors IFO 8348 & 6 & 25 & 0.10 & 0.85 & 89.9 \\
\hline C. consors IFO 8726 & 6 & 25 & 0.06 & 0.82 & 93.6 \\
\hline C. fibula IFO 4949 & 6 & 25 & 0.04 & 0.88 & 95.8 \\
\hline C. hirsutus IFO 6477 & 6 & 25 & 0.04 & 0.96 & 95.5 \\
\hline C. hirsutus IFO 6478 & 6 & 25 & 0.17 & 1.82 & 91.3 \\
\hline C. pubescens IFO 9782 & 5 & 25 & 0.20 & 2.52 & 92.5 \\
\hline C. versicolor IAM 13013 & 4 & 25 & 0.03 & 0.97 & 96.7 \\
\hline C. versicolor IFO 4937 & 5 & 25 & 0.08 & 0.84 & 91.2 \\
\hline C. versicolor IFO 4941 & 5 & 25 & 0.07 & 1.02 & 93.4 \\
\hline C. versicolor IFO 4942 & 5 & 25 & 0.09 & 0.87 & 90.7 \\
\hline C. versicolor IFO 6481 & 6 & 25 & 0.16 & 1.61 & 91.0 \\
\hline C. versicolor IFO 6482 & 6 & 25 & 0.09 & 0.85 & 90.9 \\
\hline C. versicolor IFO 7047 & 7 & 25 & 0.14 & 2.47 & 94.6 \\
\hline C. versicolor IFO 8754 & 6 & 25 & 0.12 & 1.40 & 92.0 \\
\hline Flammulina velutipes TPU 4674 & 4 & 25 & 0.51 & 1.89 & 78.8 \\
\hline Schizophyllum commune TPU 4434 & 3 & 30 & 0.15 & 1.07 & 87.7 \\
\hline S. commune IAM 9006 & 4 & 25 & 0.09 & 0.83 & 90.2 \\
\hline Verticillium dahliae TPU 4900 & 4 & 30 & 0.07 & 1.79 & 96.0 \\
\hline V. dahliae JCM 9509 & 4 & 25 & 0.09 & 1.16 & 92.8 \\
\hline V. dahliae JCM 9510 & 3 & 25 & 0.10 & 1.12 & 92.1 \\
\hline Isolated fungus I-1 & 4 & 25 & 0.13 & 1.05 & 88.8 \\
\hline
\end{tabular}

Table 3. PN-5'- $\alpha$-G-forming Activity of Selected Strains

Strains were grown aerobically on $5 \mathrm{~mL}$ of medium I or II in a test tube. The reaction was done at $40^{\circ} \mathrm{C}$ for $8 \mathrm{~h}$ in the dark with shaking in a assay mixture consisting of $100 \mathrm{~mm}$ potassium phosphate buffer ( $\mathrm{pH} 6.5)$, containing $24.7 \mathrm{mg}(0.12 \mathrm{mmol})$ of $\mathrm{PN} \cdot \mathrm{HCl}, 24 \mathrm{mg}$ of dextrin, $24 \mathrm{mg}$ of sucrose, and $1.0 \mathrm{~mL}$ of culture broth, in a total volume of $1.2 \mathrm{~mL}$. One unit of activity was defined as the activity needed to produce one $\mu \mathrm{mol}$ of $\mathrm{PN}-5^{\prime}-\alpha-\mathrm{G}$ per minute under these assay conditions.

\begin{tabular}{|c|c|c|c|c|c|c|c|}
\hline & Strain & Medium & $\begin{array}{l}\text { Culture } \\
\text { temp. } \\
\left({ }^{\circ} \mathrm{C}\right)\end{array}$ & $\begin{array}{l}\text { Culture } \\
\text { time } \\
\text { (d) }\end{array}$ & $\begin{array}{l}\text { Yield of } \\
\text { wet cells } \\
(\mathrm{mg} / \mathrm{mL})\end{array}$ & $\begin{array}{l}\text { Activity } \\
(\mathrm{U} / \mathrm{L})\end{array}$ & $\begin{array}{c}\text { 5'-Position } \\
\text { selectivity } \\
(\%)\end{array}$ \\
\hline \multirow[t]{2}{*}{ Bacterium } & \multirow{2}{*}{ Paenibacillus alvei IFO 3343} & I & 30 & 6 & 14.9 & 12.2 & 83.8 \\
\hline & & II & 30 & 6 & 34.1 & 19.6 & 84.4 \\
\hline \multirow[t]{12}{*}{ Fungi } & \multirow{2}{*}{ Coriolus fibula IFO 4949} & I & 25 & 4 & 5.5 & 3.4 & 95.8 \\
\hline & & II & 25 & 4 & 29.8 & 37.0 & 95.5 \\
\hline & \multirow[t]{2}{*}{ C. pubescens IFO 9782} & I & 25 & 11 & 16.7 & 7.7 & 93.4 \\
\hline & & II & 25 & 4 & 33.0 & 41.6 & 93.6 \\
\hline & \multirow{2}{*}{ C. versicolor IAM 13013} & I & 25 & 4 & 3.1 & 3.3 & 93.7 \\
\hline & & II & 25 & 4 & 12.9 & 8.0 & 93.9 \\
\hline & \multirow[t]{2}{*}{ Schizophyllum commune TPU 4434} & I & 25 & 6 & 6.7 & 3.8 & 80.3 \\
\hline & & II & 25 & 6 & 15.5 & 5.7 & 87.6 \\
\hline & \multirow{2}{*}{ S. commune IAM 9006} & I & 25 & 6 & 27.3 & 3.0 & 88.9 \\
\hline & & II & 25 & 6 & 80.6 & 8.0 & 88.3 \\
\hline & \multirow{2}{*}{ Verticillium dahliae TPU 4900} & I & 25 & 4 & 33.5 & 1.5 & 90.0 \\
\hline & & II & 25 & 4 & 42.7 & 25.4 & 89.1 \\
\hline \multirow[t]{2}{*}{ Isolated fungus } & \multirow[t]{2}{*}{$\mathrm{I}-1$} & I & 25 & 4 & 6.9 & 11.2 & 92.3 \\
\hline & & II & 25 & 4 & 24.5 & 13.4 & 91.7 \\
\hline
\end{tabular}




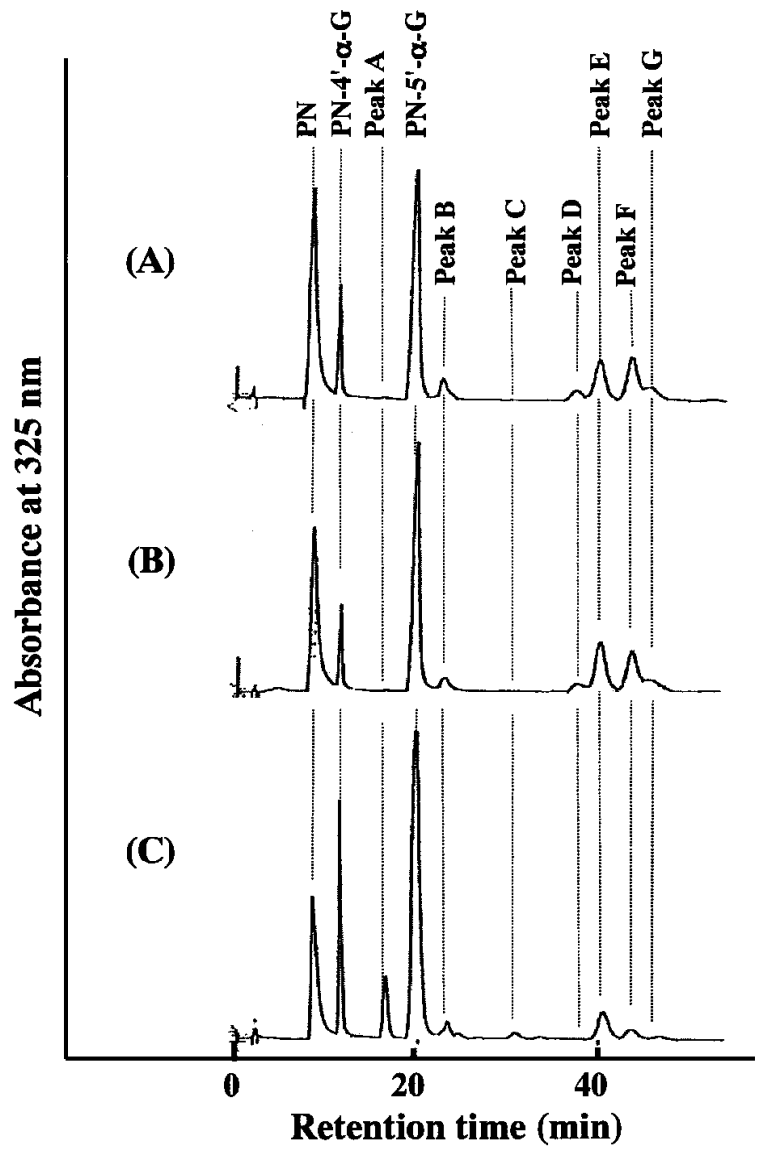

Fig. 2. HPLC of Reaction Mixtures with Intact Cells of Selected Strains.

HPLC was done as described in Materials and Methods. Reaction mixtures after $96 \mathrm{~h}$ of incubation with intact cells of $C$. fibula IFO 4949 (A), C. pubescens IFO 9782 (B), and V. dahliae TPU 4900 (C) were analyzed.
9782, the yield of $\mathrm{PN}-5^{\prime}-\alpha-\mathrm{G}$ increased during the reaction between zero to $20 \mathrm{~h}$; the yield was $27 \%$ and $30 \%$, respectively, by $20 \mathrm{~h}$, and remained there later, even when more dextrin and cells were added (Fig. 3). $V$. dahliae TPU 4900 produced $\mathrm{PN}-5^{\prime}-\alpha-\mathrm{G}$ from PN within $70 \mathrm{~h}$ in the highest molar yield, $42 \%$, of these three strains. The 5'-position selectivities of $C$. fibula IFO 4949, C. pubescens IFO 9782, and $V$. dahliae TPU 4900 were more than $90 \%$ in the early stage of the reaction, but they decreased gradually to $81 \%$, $86 \%$, and $80 \%$, respectively, by $70 \mathrm{~h}$.

The amounts of by-products (not including PN-4' $\alpha-\mathrm{G})$ were different with each strain tested. In the reaction mixtures with $C$. fibula IFO 4949 and $C$. pubescens IFO 9782 at $70 \mathrm{~h}$, the total amount of byproducts was $59 \%$ and $73 \%$, respectively, of the amount of $\mathrm{PN}-5^{\prime}-\alpha-\mathrm{G}$, and the total amount of byproducts was $30 \%$ of $\mathrm{PN}-5^{\prime}-\alpha-\mathrm{G}$ with $V$. dahliae TPU 4900. Thus, $V$. dahliae TPU 4900 gave the highest yield of $\mathrm{PN}-5^{\prime}-\alpha-\mathrm{G}$ with the smallest amount of by-products.

\section{Formation of $P N-4^{\prime}-\alpha-G$ by selected strain}

Strains that yielded PN-4' $-\alpha-\mathrm{G}$ in more than $15 \%$ molar conversion $(0.75 \mathrm{mM})$ with more than $75 \% 4^{\prime}-$ position selectivity are listed in Table 4 . They were distributed more widely than $5^{\prime}$-position selective strains: there were 11 strains in four genera of bacteria, one actinomycetes strain, one yeast strain, and six strains in three genera of fungi. Some microorganisms belonging to Verticillium had 4'-position selectivity, although other strains of the same genus had high $5^{\prime}$-position selectivity.
(A) Coriolus fibula IFO 4949

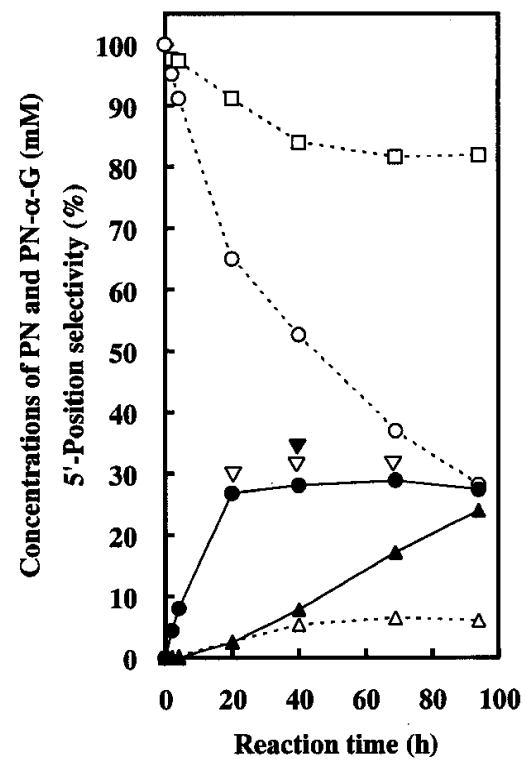

(B) Coriolus pubescens IFO 9782

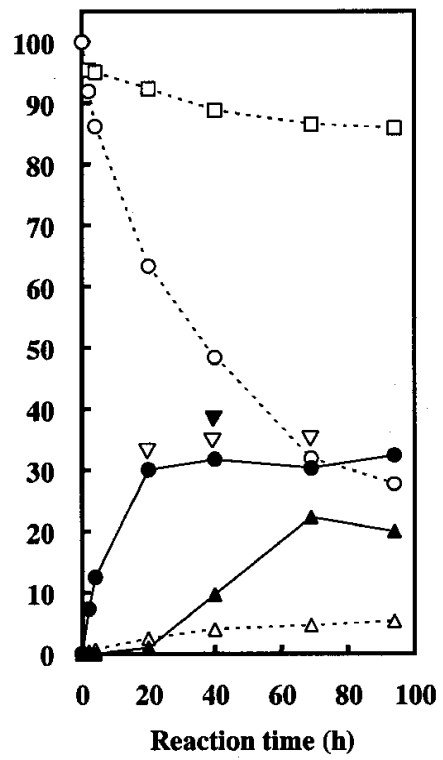

(C) Verticillium dahliae TPU $\mathbf{4 9 0 0}$

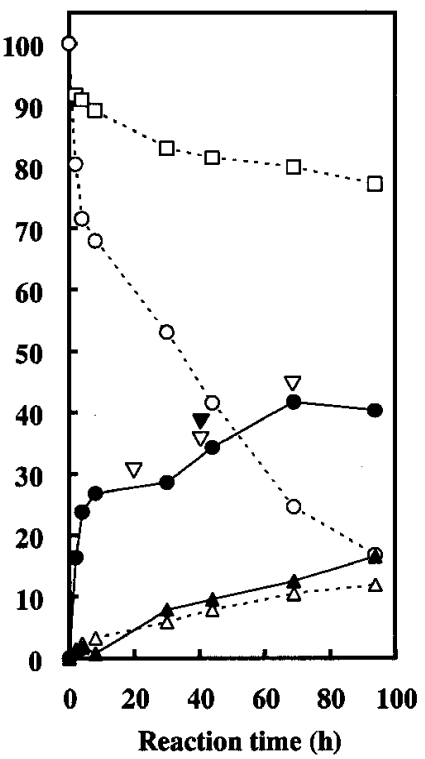

Fig. 3. Changes with Time in PN-5'- $\alpha-\mathrm{G}$ Synthesis by Intact Cells of Selected Strains.

The reactions were done as described in Materials and Methods. Symbols: $\bigcirc$, PN; $\bullet, P N-5^{\prime}-\alpha-G ; \triangle, P N-4^{\prime}-\alpha-G ; \Delta$, total amount of by-products (not including PN-4'- $\alpha-\mathrm{G}$ ); $\square, 5^{\prime}$-position selectivity; $\nabla$, addition of dextrin; $\nabla$, addition of cells. 
Table 4. Microorganisms with High 4'-Position-selective Glucosylation

\begin{tabular}{|c|c|c|c|c|c|}
\hline & \multirow{2}{*}{$\begin{array}{l}\text { Culture time } \\
\text { (d) }\end{array}$} & \multirow{2}{*}{$\begin{array}{l}\text { Culture temp. } \\
\qquad\left({ }^{\circ} \mathrm{C}\right)\end{array}$} & \multicolumn{2}{|c|}{ Compound found in culture (mM) } & \multirow{2}{*}{$\begin{array}{c}4^{\prime} \text {-Position selectivity } \\
(\%)\end{array}$} \\
\hline & & & $\mathrm{PN}-4^{\prime}-\alpha-\mathrm{G}$ & $\mathrm{PN}-5^{\prime}-\alpha-\mathrm{G}$ & \\
\hline \multicolumn{6}{|l|}{ Bacteria } \\
\hline Bacillus cereus TPU 5504 & 4 & 30 & 0.92 & 0.04 & 96.0 \\
\hline B. cereus TPU 5543 & 3 & 30 & 0.86 & 0.11 & 88.6 \\
\hline B. megaterium TPU 5522 & 4 & 30 & 1.34 & 0.17 & 88.9 \\
\hline B. megaterium TPU 5525 & 3 & 30 & 0.98 & 0.29 & 77.4 \\
\hline Edwardsiella hoshinae TPU 6101 & 4 & 30 & 0.84 & 0.04 & 95.9 \\
\hline Ochrobactrum anthropi TPU 6850 & 4 & 30 & 0.89 & 0.06 & 93.9 \\
\hline Serratia marcescens TPU 7300 & 4 & 30 & 1.03 & 0.07 & 93.5 \\
\hline S. marcescens TPU 7302 & 4 & 30 & 1.24 & 0.33 & 79.0 \\
\hline S. marcescens TPU 7303 & 4 & 30 & 1.12 & 0.18 & 85.9 \\
\hline S. marcescens TPU 7309 & 4 & 30 & 1.26 & 0.14 & 90.4 \\
\hline Isolated Bacillus sp. strain F-2-1 & 3 & 30 & 1.18 & 0.10 & 92.0 \\
\hline \multicolumn{6}{|l|}{ Actinomycetes } \\
\hline Nocardia flavorosea TPU 3019 & 5 & 30 & 1.01 & 0.28 & 78.5 \\
\hline \multicolumn{6}{|l|}{ Yeast } \\
\hline $\begin{array}{l}\text { Saccharomyces heterogenicus } \\
\text { TPU } 1043\end{array}$ & 7 & 30 & 1.37 & 0.05 & 96.6 \\
\hline \multicolumn{6}{|l|}{ Fungi } \\
\hline Mortierella sp. TPU 4802 & 4 & 30 & 1.68 & 0.39 & 81.3 \\
\hline M. isabellina TPU 4808 & 4 & 30 & 1.00 & 0.27 & 78.7 \\
\hline Tritirachium dependens IFO 9390 & 5 & 25 & 1.15 & 0.30 & 79.3 \\
\hline T. oryzae IFO 7544 & 4 & 25 & 1.03 & 0.27 & 79.4 \\
\hline $\begin{array}{l}\text { Verticillium fungilcola var. } \\
\text { aleophilum IFO } 30621\end{array}$ & 5 & 25 & 0.83 & 0.11 & 88.5 \\
\hline V. niveostratosum IFO 5435 & 4 & 25 & 1.13 & 0.30 & 79.0 \\
\hline
\end{tabular}

B. cereus TPU 5504 was one of the strains with highest $4^{\prime}$-position selectivity (96\%), so intact cells of this strains cultured with medium I in a flask were examined for PN-4' $-\alpha-\mathrm{G}$ synthesis in the same way as for $\mathrm{PN}-5^{\prime}-\alpha-\mathrm{G}$ production (Fig. 4). Even at the high PN concentration $(100 \mathrm{mM})$, the strains produced PN-4' $-\alpha-\mathrm{G}$ in high yield (33\%) and with high $4^{\prime}$-position selectivity (90\%) within $19 \mathrm{~h}$. In spite of addition of dextrin and cells at $26 \mathrm{~h}$, the yield of PN-4 ${ }^{\prime}-\alpha-\mathrm{G}$ remained almost constant at $30 \%$ and the $4^{\prime}$-position selectivity decreased gradually to $80 \%$ by $48 \mathrm{~h}$.

\section{Discussion}

Pyridoxine, often used as one of vitamins of the $\mathrm{B}_{6}$ complex, is unstable in the light, especially in a neutral solution. ${ }^{11-13)}$ However, it is almost certain that PN-5' $-\alpha-\mathrm{G}$ has both nutritional importance as vitamin $B_{6}$ and stability against light and heat, probably because of the masking effect by the glucosyl group at its $5^{\prime}$-position. $\mathrm{PN}-\alpha-\mathrm{G}$ is be more stable than pyridoxine to irradiation with ultraviolet light and to being heated. ${ }^{2)}$ The bioavailability of $\mathrm{PN}-\alpha-\mathrm{G}$ is similar to that of PN, according to results of a long-term feeding experiment with rats. ${ }^{14)}$ The two positional isomers of $\mathrm{PN}-\alpha-\mathrm{G}$ enter liver cells to a similar extent. However, during a $60-\mathrm{min}$ incubation with rat liver cells, $78 \%$ of $\mathrm{PN}-5^{\prime}-\alpha-\mathrm{G}$ is hydrolyzed, but only $15 \%$ of $\mathrm{PN}-4^{\prime}-\alpha-\mathrm{G}$ is metabolized. ${ }^{4)}$

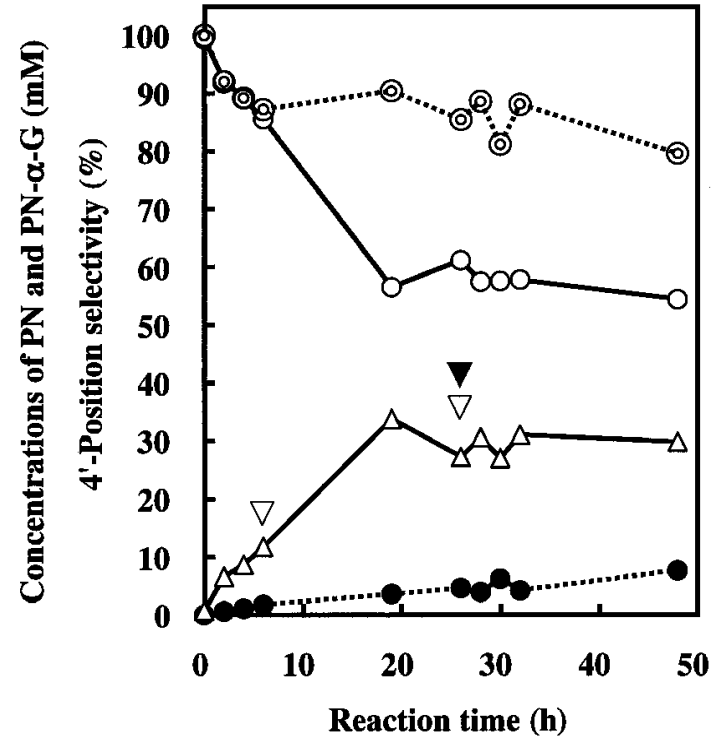

Fig. 4. Changes with in $\mathrm{PN}-4^{\prime}-\alpha-\mathrm{G}$ Synthesis by Intact Cells of B. cereus TPU 5504.

The reaction was done as described in Materials and Methods. Symbols: $\bigcirc, \mathrm{PN}$; •, PN-5'- $\alpha-\mathrm{G} ; \triangle, \mathrm{PN}-4^{\prime}-\alpha-\mathrm{G}$; ○), $4^{\prime}$-position selectivity; $\nabla$, addition of dextrin; $\nabla$, addition of cells.

It is necessary for the industrial production of $\mathrm{PN}$ $5^{\prime}-\alpha-\mathrm{G}$ to introduce a glucosyl group into PN anomer selectively and the $5^{\prime}$-position selectively, because of difficulties in separating $\mathrm{PN}-5^{\prime}-\alpha-\mathrm{G}$ from $\mathrm{PN}-4^{\prime}-\alpha-\mathrm{G}$, 
with their similar physical characteristics. Therefore, an enzymatic method would be suitable for such production of $\mathrm{PN}-5^{\prime}-\alpha-\mathrm{G}$, if an enzyme or microorganism that will glucosylate $\mathrm{PN}$ with high $5^{\prime}$-position selectivity and high yield can be found.

The main drawback of the first strain found to produce a large proportion of $\mathrm{PN}-5^{\prime}-\alpha-\mathrm{G}$ to $\mathrm{PN}-4^{\prime}-\alpha-$ $\mathrm{G},{ }^{3)}$ Micrococcus luteus IFO 3232, was the little PN$\alpha$-G produced: yield was about $6.5 \%$ from $98 \mathrm{~mm}$ PN and $146 \mathrm{~mm}$ sucrose in the intact-cells reaction. ${ }^{5)}$ Another microorganism, Micrococcus sp. strain no. 431 was found by screening with a medium including sucrose as the carbon source from 28 genera of culture collections and isolates from nature, ${ }^{15)}$ the $\mathrm{PN}-\alpha$ G-forming activity of that strain was similar to that of $M$. luteus IFO 3232.

Carbon sources of screening media for transglucosylation activity should be chosen with their several roles in mind; the substance will be not only carbon source for the growth of microorganisms, but also a glucosyl group donor in transglucosylation, and an inducer of transglucosylation activity. We selected sucrose and dextrin as carbon sources of our screening medium for the reasons given below. Some of enzymes catalyzing the formation of $\mathrm{PN}-\alpha-\mathrm{G}$ can not use sucrose as a glucosyl group donor, ${ }^{6,7)}$ although many microorganisms can use sucrose as a carbon source. One half of the glucosyl group of maltose seems not to be used by transglucosylation, but it is used as a carbon source in the screening medium for the formation of $4^{\prime}-O-(\alpha$-D-glucopyranosyl)-D-pantothenic acid ${ }^{16)}$ and $l$-menthyl $\alpha$-Dglucopyranoside. ${ }^{17)}$ If dextrin or soluble starch were used as the carbon source, some microorganisms might not grow on the screening medium. We obtained novel $5^{\prime}$ - and $4^{\prime}$-positon-selective strains that formed $\mathrm{PN}-\alpha-\mathrm{G}$ not only by using a newly devised screening medium, but also by extensive microbial screening from stock cultures (907 strains from 129 genera) and from nature (63 strains).

The ability of microbial cultures to produce $\mathrm{PN}-5^{\prime}$ $\alpha-\mathrm{G}$ with high $5^{\prime}$-position selectivity was found in several genera of fungi, for example Coriolus (Basidiomycotina) and Verticillium (Deuteromycetes). Members of Coriolus are called wood-rotting fungi and some species of Verticillium are pathogenic to plants. These two genera can degrade structural compounds of plants. ${ }^{18-21)}$ Therefore, the $\beta$-glucosidase activity of these genera has been examined more than the $\alpha$-glucosidase activity. It is not known whether one enzyme glucosylates PN with $80-90 \%$ regioselectivity, or whether other enzymes with different regioselectivity also exist. We are interested also in the function of regioselective transglucosylation of these fungi in nature. Intact cells of $C$. fibula IFO 4949, C. pubescens IFO 9782, and $V$. dahliae TPU 4900, catalyzed the synthesis of $\mathrm{PN}-5^{\prime}-\alpha-\mathrm{G}$ from $100 \mathrm{~mm} \mathrm{PN}$ in yields five to eight times (27\%,
$30 \%$, and $42 \%$, respectively) higher than the previously reported microorganisms $M$. luteus IFO 3232 and with the same or higher $5^{\prime}$-position selectivity (91\%, 92\%, and 80\%, respectively).

\section{References}

1) Tsuge, H., Maeno, M., Hayakawa, T., and Suzuki, $\mathrm{Y}$., Comparative study of pyridoxine- $\alpha, \beta$-glucosides, and phosphopyridoxyl-lysine as vitamin $\mathrm{B}_{6}$ nutrient. J. Nutr. Sci. Vitaminol., 42, 377-386 (1996).

2) Kawai, F., Yamada, H., and Ogata, K., Properties of pyridoxine glucoside. J. Vitaminol., 17, 121-124 (1971).

3) Ogata, K., Uchida, Y., Kurihara, N., Tani, Y., and Tochikura, T., Studies on transglycosidation to vitamin $\mathrm{B}_{6}$ by microorganisms: II. Chemical structure of pyridoxine glucoside. J. Vitaminol., 15, 160-166 (1969).

4) Joseph, T., Tsuge, H., Suzuki, Y., and McCormick, D. B., Pyridoxine $4^{\prime}-\alpha$ - and $5^{\prime}-\alpha$-D-glucosides are taken up and metabolized by isolated rat liver cells. $J$. Nutr., 126, 2899-2903 (1996).

5) Ogata, K., Tani, Y., Uchida, Y., and Tochikura, T., Studies on transglycosidation to vitamin $\mathrm{B}_{6}$ by microorganisms: I. Formation of a new vitamin $\mathrm{B}_{6}$ derivative, pyridoxine glucoside by Sarcina lutea. $J$. Vitaminol., 15, 142-150 (1969).

6) Suzuki, Y., Doi, Y., Uchida, K., and Tsuge, H., Enzymatic preparation of pyridoxine $4^{\prime}-$ and $5^{\prime}-\alpha$-Dglucosides. Methods Enzymol., 280, 66-71 (1997).

7) Yamamoto, T., Hosokawa, T., Kishihara, S., Tamaki, H., Wakiuchi, N., and Suzuki, Y., Study of favorable conditions in formation of pyridoxineglucosides by catalysis of CGTase. Seito Gijyutsu Kenkyu Kaishi (in Japanese), 46, 49-56 (1998).

8) Tsuge, H., Joseph, T., McCormick, D. B., and Suzuki, Y., Abstracts of papers presented by the Vitamin B Society in Japan. Vitamins (in Japanese), 70, 275 (1996).

9) Tilden, E. B., and Hudson, C. S., Preparation and properties of the amylases produced by Bacillus macerans and Bacillus polymyxa. J. Bacteriol., 43, 527-544 (1942).

10) Sneath, P. H. A., Mair, N. S., Sharpe, M. E., and Holt, J. G., Bergey's Manual of Systematic Bacteriology, vol. 2, Section 13 Endospore-forming grampositive rods and cocci. Williams \& Wilkins, Baltimore, pp. 1104-1139 (1986).

11) Hochberg, M., Melnick, D., and Oser, B. L., On the stability of pyridoxine. J. Biol. Chem., 155, 129-136 (1944).

12) Cunningham, E., and Snell, E. E., The vitamin $B_{6}$ group: VI. The comparative stability of pyridoxine, pyridoxamine, and pyridoxal. J. Biol. Chem., 158, 491-495 (1945).

13) Ikeda, S., Oka, T., Ohishi, N., and Fukui, S., Photochemistry of vitamin $\mathrm{B}_{6}$ : I. Photodecomposition of pyridoxine. (1) Oxidation of side chains at 4- and 5position. Vitamins (in Japanese), 38, 109-115 (1968).

14) Maeno, M., Morimoto, Y., Hayakawa, T., Suzuki, Y., and Tsuge, H., Feeding experiments of 
pyridoxine derivatives as vitamin $\mathrm{B}_{6}$. Int. J. Vit. Nutr. Res., 67, 444-449 (1997).

15) Tani, Y., Kawai, F., Uchida, Y., Tochikura, T., and Ogata, K., Studies on transglycosidation to vitamin $\mathrm{B}_{6}$ by microorganisms, III. Distribution of activity of pyridoxine glucoside formation in microorganisms. $J$. Vitaminol., 15, 167-173 (1969).

16) Kawai, F., Maezato, K., Yamada, H., and Ogata, K., Microbial formation of D-pantothenic acid- $\alpha$-glucoside. Agric. Biol. Chem., 42, 1675-1679 (1978).

17) Nakagawa, H., Dobashi, Y., Sato, T., Yoshida, K., Tsugane, T., Shimura, S., Kirimura, K., Kino, K., and Usami, S., $\alpha$-Anomer-selective glucosylation of menthol with high yield through a crystal accumulation reaction using lyophilized cells of Xanthomonas campestris WU-9701. J. Biosci. Bioeng., 89, 138-144 (2000).
18) Howell, C. R., Differential enzyme synthesis by haploid and diploid forms of Verticillium alboatrum. Phytopathology, 60, 488-490 (1970).

19) Calonje, M., Garcia Mendoza, C., Galan, B., and Novaes-Ledieu, M., Enzymatic activity of the mycoparasite Verticillium fungicola on Agaricus bisporus fruit body cell walls. Microbiology, 143, 2999-3006 (1997).

20) Elisashvii, V. I., Khardziani, T. S., Tsiklauri, N. D., and Kachishvili, E. T., Cellulase and xylanase activities in higher basidiomycetes. Biochemistry (Moscow), 64, 718-722 (1999).

21) Tsujiyama, S., Sumida, K., and Ueno, H., Influence of vanillin on the production of cellulolytic and xylanolytic enzymes from a wood-rotting fungus, Coriolus versicolor. Mycoscience, 41, 527-532 (2000). 